\title{
INFORMATION SYSTEM AND PRODUCTION PROCESS CONTROL
}

\author{
Nota dei m.e. ANGELO ZANELLA (*) e EGIDIO CASCINI (**)
}

(Adunanza del 5 marzo 2015)

SUNTO. - Si inizia con la definizione dei dati sperimentali. In primo luogo le variabili di controllo. Queste hanno livelli stabiliti dallo sperimentatore con riferimento ad un "modello" teorico, che definisce le componenti del sistema di produzione, il loro collegamento e le "leggi" di funzionamento per raggiungere gli obiettivi propostisi. Poi, le risposte o risultati delle attività di produzione, che tipicamente hanno carattere aleatorio. Le variabili di controllo servono a regolarne la posizione delle distribuzioni, e la loro variabilità nelle sue diverse connotazioni (diciamo approccio di Taguchi). Un sistema informativo che rappresenta una raccolta di dati orientata al controllo di aspetti specifici quali: il controllo finanziario, il controllo contabile, il controllo del personale, il controllo commerciale - relativo agli ordinativi, alle spedizioni ed al soddisfacimento dei clienti - il controllo degli approvvigionamenti, il controllo di produzione, articolato nel controllo dei programmi di produzione, nel controllo delle linee di produzione e relativa manutenzione, il controllo della qualità, articolato nel controllo tecnico di conformità dei prodotti a determinate specifiche, nell' assicurazione nel tempo della "buona qualitä" dei prodotti. Un orientamento qualitativo alla scelta dei dati da inserire nel sistema informativo del controllo della qualità è che deve avvicinarsi il più possibile ad essere sufficiente, nel senso che sia atto a spiegare ogni anomalia riscontrata nelle caratteristiche del prodotto, e completo nel senso che sia atto a suggerirne la correzione. Il controllo della qualità si presenta quale dinamico in quanto richiede in via naturale il miglioramento sistematico delle condizioni di regolazione delle attività produttive - a partire da una condizione di riferimento. Si considerano due esempi appropriati ad illustrare gli aspetti fondamentali di una metodologia generale utile per trattare questo complesso argomento. Il primo esempio concerne un'applicazione industriale riguardante il controllo del processo di produzione del cloruro di polivinile, disponibile in

(*) Università Cattolica del S. Cuore, Milano, Italia.

(*) Associazione Italiana Cultura Qualità, Milano, Italia.

E-mail: info@istitutolombardo.it 
letteratura [9]. Il secondo esempio concerne il processo di distribuzione di beni deperibili, che consideriamo innovativo. In questo si assume un numero finito di situazioni (punti di vendita) e che si può definire un indicatore $Q=Q_{1} / c=$ Qualità di un prodotto di riferimento/una corrispondente grandezza economica (costo o ricavo). Nel caso considerato l'andamento ordinato dei rapporti costo totale/ricavi totali consente di stabilire la situazione economicamente più vantaggiosa.

$* * *$

ABSTRACT. - We start with the definition of experimental data. First place we consider the controllable variables, whose levels are established by technical production experts with regard to a theoretic "model" defining the production components, their connections and working rules in sight of the envisaged achievements. Then, the responses or results of production activities, which typically show random variability. The controllable variables are used to regulate the means of their distributions and aspects of variability (Taguchi approach). An information system represents a data collection, which is directed to specific purposes like: financial control, accounting control, personnel control, business control, production control, framed around production programs, control of production lines and related maintenance, quality control, framed around control of nonconformities regarding some specification limits and ensuring product good quality over time. Qualitative guidelines for choosing the data for a quality control information system are that it must be as near as possible to a sufficient system which means that it is capable of explaining any nonconformity in a product characteristic, as well as being complete, that is, such that it is also capable of suggesting how to remove them. In a natural way quality control implies a dynamic approach based on a systematic improvement of production activities, starting from specific reference conditions. We consider two examples appropriated to explain the fundamentals of a methodology useful to cope with this complex subject. The first example refers to a real industrial application regarding the process control of polyvinyl chloride production, found in literature [9]. The second example concerns the distribution process of perishable goods, which is considered to be an innovation. In this case we suppose that there is a finite set of operating situations (points of sale) and that we can define an indicator $Q=Q_{1} / \mathrm{c}=$ Quality of a reference product/a corresponding economic quantity (cost or earning). In the case considered, by means of the ordering of the ratios total cost/total earning, we come to the most profitable situation.

\section{INTRODUCTION}

This paper is divided into two parts; the first one concerns the technical aspects of a system for the quality control of a production process, and the second one concerns the economical aspects connected to the system.

We will try to clarify the above concepts by giving two examples. The first one concerns the process control of polyvinyl chloride production, found in literature [9], the second one concerns the distribution process of perishable goods, which is considered to be an innovation. 


\section{AN OUTLINE REGARDING THE MOST SIGNIFICANT DEFINITIONS}

1.1 The quality concerns overall aspects and characteristics of a product/a service which can assure the capacity to satisfy specific requirements ([1], [8], [10].

1.2 Control of a dynamic physical system which includes some aspects: reference to a technical project - theoretical model - which can define the components of the system, the links and the laws or regulations of their operation in order to reach the aims of the model; this includes:

- a concrete carrying out of the model;

- a series of operations which can ascertain, in the future, if the condition of the system conforms or not with the condition prescribed by the model;

- a series of operations which can allow to bring back the system to the conditions prescribed by the model. These correspond to the control variables $\boldsymbol{t}_{\boldsymbol{h}}$. These have levels $\boldsymbol{t}_{\boldsymbol{h}}{ }^{0}$ established by the experimenter, making reference to the theoretical model.

Then, the answers or the results of the production activities, which have a typical random characteristic. The control variables have the purpose of regulating the distributions, especially the centering, but they may regulate even the variability (have regard to Taguchi approach) ([4], [11]).

1.3 An information system represents a number of data oriented, in general, to control specific aspects of a production system such as: financial control, accounting control, personnel control, trade control concerning the orders, shipments and the customer satisfaction, provisioning control, production control articulated in the production programming control, the operational control of the production line and its relative maintenance, quality control, articulated in the technical control up to the products with determined specifications and adequacy in order to assure also in the future a "good quality".

A qualitative guidance to choose data to place in the information system of the quality quality control is that it should be the closest possible to be sufficient, that is to be well-suited to explain every anomaly found in the characteristics of the products and complete, that is wellsuited to suggest an appropriate correction. 


\section{THE TWO PROPOSED EXAMPLES}

2.1 Let us consider the first example, found in literature [9], concerning the statistical control of a chemical process of polymerizing of vinyl chloride [9].

In a chemical process there are 4 kinds of variables:

a) random variables concerning raw materials;

b) random variables concerning the process;

c) random variables concerning the characteristics of the product;

d) controllable fixed effects variables.

Controllable variables, or fixed effects variables $t_{h}$, establish the production procedure, and permit their adjustment. For an assigned procedure you can consider that the values of the controllable variables are initially placed at assigned levels $t_{b}{ }^{0}$.

The following prospect shows an information system, considered to be sufficient and complete, regarding the case of the polymerizing process taken as an example. The diagram indicates several kinds of variables - each corresponding to a rectangle, and sometimes the name is omitted for privacy sake - random variables relative to the raw materials (a), random variables relative to the process: drier and kettle (b), random variables relative to the product (c), controllable fixed effects variables (d). The view is completed, where possible, with the dashed lines indicating the links among the variables. We did not do it here, for sake of simplicity, but it is indicated in the original work [9]. To obtain or to confirm known links among random variables, the test of the simple correlation coefficient among couples, has been very useful. The black line suggests, just as an example, a simple correction carried out on the drier cleaning, in order to reduce the contamination in the polymer.

To orientate the control, in a very complex situation, we had to refer to an interpretative model, even if it is sometimes conventional.

Let consider the three categories or types of random variables $X_{j}^{(\mathrm{a})}, X_{k}^{(\mathrm{b})}, Y_{i}^{(\mathrm{c})}$ : of type (a) different raw materials $X j^{(\mathrm{a})}, j=1,2, \ldots, n_{a}$, which implies that they are in number of $n_{a}=n(\mathrm{a})$, say; of type (b) process aspects $X_{k}^{(b)}, k=1,2, \ldots, n_{b}$, which implies that they are in number of $n_{b}=n(\mathrm{~b})$, say; of type (c) product characteristics $Y_{i}^{(\mathrm{c})}, i=1,2, \ldots, n_{\mathrm{c}}$, which implies that they are in number of $n_{\mathrm{c}}=n(\mathrm{c})$, say. For a given $i$, each corresponding row vector $n \times 1, n=n_{a}+n_{b}+1 \times 1=n(\mathrm{a})+n(\mathrm{~b})+1 \times 1$, becomes:

$$
V_{i}^{\prime}=\left(Y_{i}^{(\mathrm{c})}, X_{1}^{(\mathrm{a})}, \ldots, X_{n(\mathrm{a})}^{(\mathrm{a})}, X_{1}^{(\mathrm{b})}, \ldots, X_{n(\mathrm{~b})}^{(\mathrm{b})}\right) .
$$




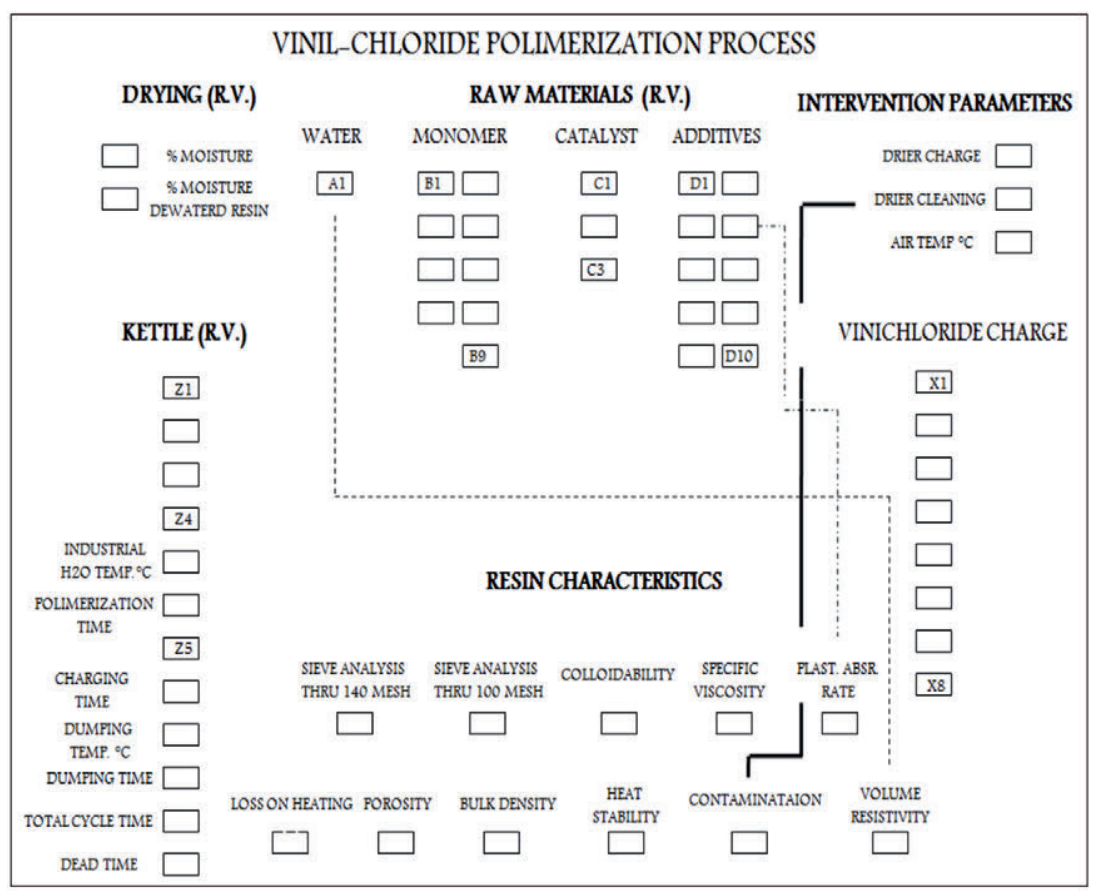

For sake of clarity, suppose for instance that $j=1$ may indicate a catalyst, $j=2$ an additive, whose structure is in turn characterized by the random variables $X_{1}{ }^{(a)}, j=1 ; X_{2}^{(a)}, j=2$. In order to setup a reference model, often only conventional, we assume that $V_{i}$ has a multivariate normal distribution ([3], [7]). In row form, the respective marginal means will be:

$$
\mathrm{E}\left(\mathrm{V}_{\mathrm{i}}{ }^{\prime}\right)=\left(\mu_{i}, \mu_{1}{ }^{(\mathrm{a})} \mu_{2}{ }^{(\mathrm{a})} \ldots \mu_{\mathrm{n}(\mathrm{a})}{ }^{(\mathrm{a})}, \mu_{1}{ }^{(\mathrm{b})} \mu_{2}{ }^{(\mathrm{b})} \ldots \mu_{n}(\mathrm{~b})^{(\mathrm{b})}\right)
$$

where $\mu_{i}$ is a scalar for a given $i, \mu_{j}^{(a)}, j=1,2, \ldots, n_{a}$ constitute a row vector of dimension $n_{a}, \mu_{k}$ (b), $k=1,2, \ldots, n_{b}$ constitute a row vector of dimension $n_{b}$, with a corresponding variance - covariance matrix $\Sigma^{(\mathrm{I})}$, considered as constant for the process under investigation.

From the regression theory, in case of a multivariate normal variable, we know that the random values of a specific component $Y_{i}^{(\mathrm{c})}$, conditioned by the values of the other components $X_{j}^{(\mathrm{a})}, X_{k}^{(\mathrm{b})}$, show a conditional mean - regression function - which is linear in the parameters $\beta_{j i}{ }^{(\mathrm{a})}, \beta_{k i}{ }^{(\mathrm{b})}$ obtained according to the criteria of the least squares 
on the basis of the elements of $\Sigma^{(i)}$, see Graybill [6] p. 64, plus an error $\varepsilon$ of zero mean, normally distributed, with independent values, in the case of repetitions. To be precise, we obtain the following expression for the conditional mean of the product random characteristic $Y_{i}^{(\mathrm{c})}$ :

$\mathrm{E}\left[\left(\mathrm{Y}_{i}{ }^{(\mathrm{c})} \mid x_{1} .{ }^{(\mathrm{a})}, \ldots, x_{\mathrm{n}(\mathrm{a})}{ }^{(\mathrm{a})}, x_{1}{ }^{(\mathrm{b})}, \ldots, x_{\mathrm{n}(\mathrm{b})}{ }^{(\mathrm{b})}\right)\right]=\beta_{0 i}+\Sigma_{\mathrm{j}} \beta_{j i}{ }^{(\mathrm{a})} x_{j i}{ }^{(\mathrm{a})}+\Sigma_{\mathrm{k}} \beta_{k i}{ }^{(\mathrm{b})} x_{k i}{ }^{(\mathrm{b})}$,

where

$$
\beta_{0 i}=\mu_{i}-\Sigma_{\mathrm{j}} \beta_{j i}{ }^{(\mathrm{a})} \mu_{j i}{ }^{(\mathrm{a})}-\Sigma_{\mathrm{k}} \beta_{k i}{ }^{(\mathrm{b})} \mu_{k i}^{(\mathrm{b})}
$$

is the mean of the characteristic of interest $Y_{i}^{(\mathrm{c})}$, deprived from the mean effects of the explicative variables and the typical nonconformities are thus expressed as variations of $\mu_{i}$, which can be corrected with suitable variations of the levels $\boldsymbol{t}_{\boldsymbol{h}}{ }^{\boldsymbol{}}$ of the controllable variables; the conditioning values $x_{j i}{ }^{(\mathrm{a})}, x_{k i}{ }^{(\mathrm{b})}$, relative to the characteristic of the product $Y_{i}^{(\mathrm{c})}$, are the ones derived from the explicative random variables $X_{1}^{(a)}, \ldots, X_{n(a)}^{(a)}$, $X_{1}{ }^{(\mathrm{b})}, \ldots, X_{n(\mathrm{~b})}{ }^{(\mathrm{b})}$ concerning raw materials and the productive process. This is done by referring to the sample general vector of observations, say the $s_{t h}$, but with $s$ an index omitted for sake of simplicity.

In order to establish the statistical control of a production process, as complex as the one under investigation, we referred to a working team with:

- an expert at statistical control;

- an engineer with a thorough technical knowledge of the process;

- a representative of the laboratory responsible for the chemical analysis;

- the responsible for the production department.

The working team has looked at the drawing of the diagram containing the variables to the previous map, indicating also the links on the basis of the available data and on the probable hypothesis to verify.

Once we established the systematic links of the control variables with the average values of the random variables, mainly the ones of the final product, the system will require to gather together, in one single place, the statistical control charts for all the random variables, stored in a way so that you can have an immediate vision.

Below, there is a simple example to have a complete use of the control charts. 

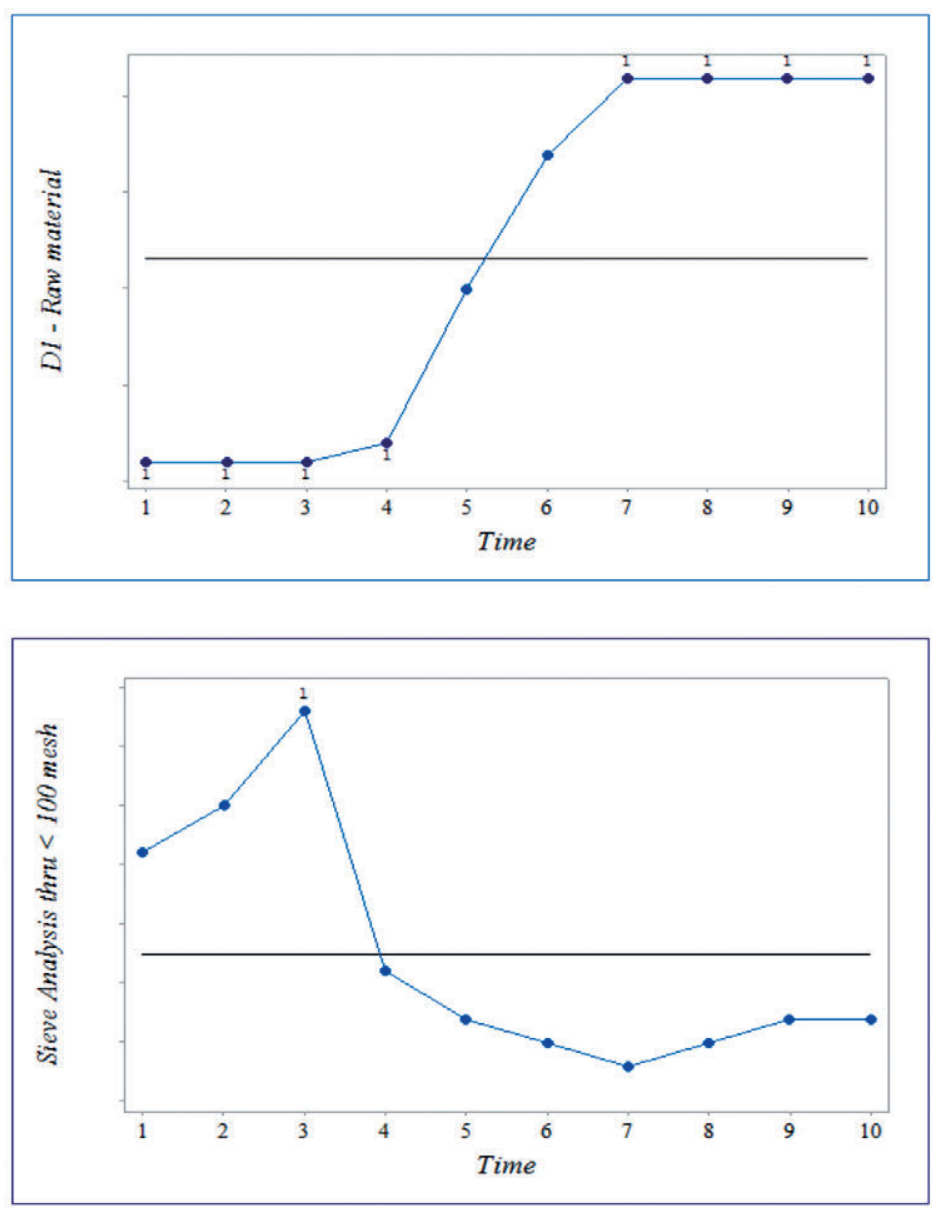

The first graph shows a random increase of reactivity of the addictive $\mathrm{D}_{1}$ of the monomer, the second one a correspondent decreasing slope of the polymer Sieve Analysis, (a fraction less than 100 mesh): no corrective interventions had to be carried out due to the favorable circumstance taken into consideration.

2.2 Now, let us consider the second example regarding the distribution process of perishable goods - in which the productive process is identified with the organizational system - which clearly takes into consideration the economical aspect. This with regard to the method outlined 
in literature [9]. In said paper as an indicator to the real or technical quality, we formally define a function $\mathrm{Q}_{1}\left[\mathrm{x}_{1}(\xi), \mathrm{x}_{2}\left((\xi), \ldots \ldots, \mathrm{x}_{\mathrm{k}}(\xi)\right.\right.$, $\left.\mathrm{z}_{1}(\xi), \mathrm{z}_{2}(\xi), \ldots, \mathrm{z}_{\mathrm{m}},(\xi) ; \mathrm{c}\right]$ which qualifies the result of the process, where $\mathrm{x}_{\mathrm{i}}, \mathrm{i}=1,2, . ., \mathrm{k}$, indicate objective variables of a physical kind, related to "fitness for use" or "user needs", $z_{j}$ which we can attribute to both produced units and organizational performance, and the vector $\xi^{\prime}=\left(\xi_{1}, \xi_{2}, \ldots \xi_{s}\right)$ to the results of the operations of the process, even of an organizational kind. In the case of perishable goods which we are examining, we considered a chosen interval of time as reference, say one month, and we take into consideration respectively the arithmetic mean of the unitary earnings and of the unitary costs in the days of that period; we can distinguish 5 different points of sale. We set for the technical or real quality $\mathbf{Q}_{1}$ in each of the different points of sale:

$$
\begin{gathered}
\mathrm{Q}_{1}=1 /[1-(\text { ordered quantity }- \text { sold quantity }) / \text { ordered quantity }]= \\
1 /\left[1-\left(Q_{o}-Q_{s}\right) / Q_{O}\right]= \\
=1 /(\text { sold quantity/ordered quantity })=Q_{o} / Q_{s}= \\
\text { Ordered quantity/sold quantity. }
\end{gathered}
$$

For the real Quality, in the same period, we noted down the values in 5 points of sale of the same product. We could assume that they had a nearly normal distribution even if their means were estimated by the arithmetic means and the standard deviations by the usual formulas, with the estimates replacing the unknown true parameters $\mu$ and $\sigma$.

Consider in each of the 5 cases the constant average cost c, inclusive of the total cost of the point of sale in the period, as the ratio:

$$
\begin{aligned}
& \mathrm{c}=\text { (average unitary earning from selling/average unitary cost of order) } \\
& \qquad=\mathrm{c}_{\mathrm{s}} / \mathrm{c}_{\mathrm{O}}>1,
\end{aligned}
$$

and dividing by $\mathrm{c}$ we obtain the following:

virtual quality $Q_{1} / \mathrm{c}=Q_{o} / Q_{s} /\left[\mathrm{c}_{\mathrm{s}} / \mathrm{c}_{\mathrm{o}}\right]=Q_{o} \mathrm{c}_{\mathrm{o}} / Q_{s} \mathrm{c}_{\mathrm{s}}=$ total cost $/$ total earning. Historically, it has been noticed that the programmed and ordered product was always greater than the sold. However this does not matter provided that (total cost/total earning) $<1$.

The following schemes illustrate the main elements of the second example. 
THE PROCESS

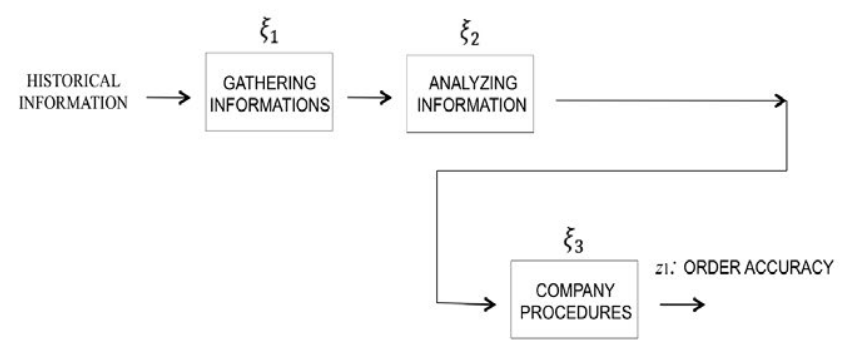

LET US DEFINE A VECTOR:

$\xi=\left(\xi_{1} \text { : GATHERING INFORMATION, } \xi_{2}: \text { ANALYZING INFORMATION } \xi_{3}: \text { PROCEDURES }\right)^{\prime}$

$\xi_{1}$ INFORMATION

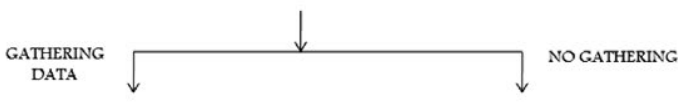

AVAILABLE DATA

NO DATA

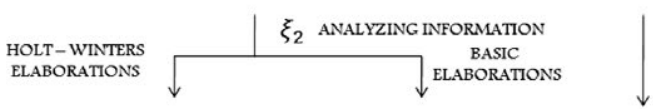

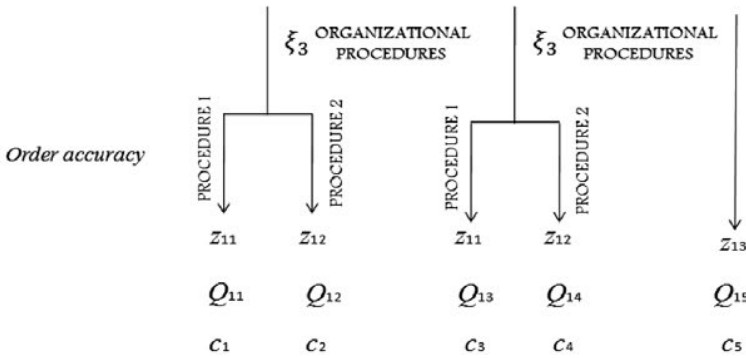

Note the following adaptation of the second example to the pattern of a sufficient and complete information system. All responses of interest sufficiency:

Monthly ordered quantity

Monthly sales

Real Quality $\mathrm{Q}_{1}=$ (monthly ordered quantity/monthly sold quantity)

Organizational procedures: $\xi_{1}, \xi_{2}, \xi_{3}$

Virtual Quality $=($ costs/earnings $)=\mathrm{Q}_{\mathrm{o}} \cdot \mathrm{c}_{\mathrm{o}} / \mathrm{Q}_{\mathrm{s}} \cdot \mathrm{c}_{\mathrm{s}}=$ (monthly ordered quan tity $\cdot$ unitary mean cost $) /($ monthly sold quantity $\cdot$ unitary mean earning); 
Taking corrective action on trends: completeness:

monthly ordered quantity: Order reduction or increase

monthly sold quantity: Price reduction

real Quality: Order reduction

virtual Quality: price reduction

Organizational procedures: suitable adjustments.

In order to check out the correctness of the system by means of some equivalent new data we considered a Monte Carlo simulation of 30 observations from the Normal distributions assumed above for each of the 5 cases. The results are given in the Table underneath and in the pertinent graphs. The corresponding Random numbers are reported in Appendix.

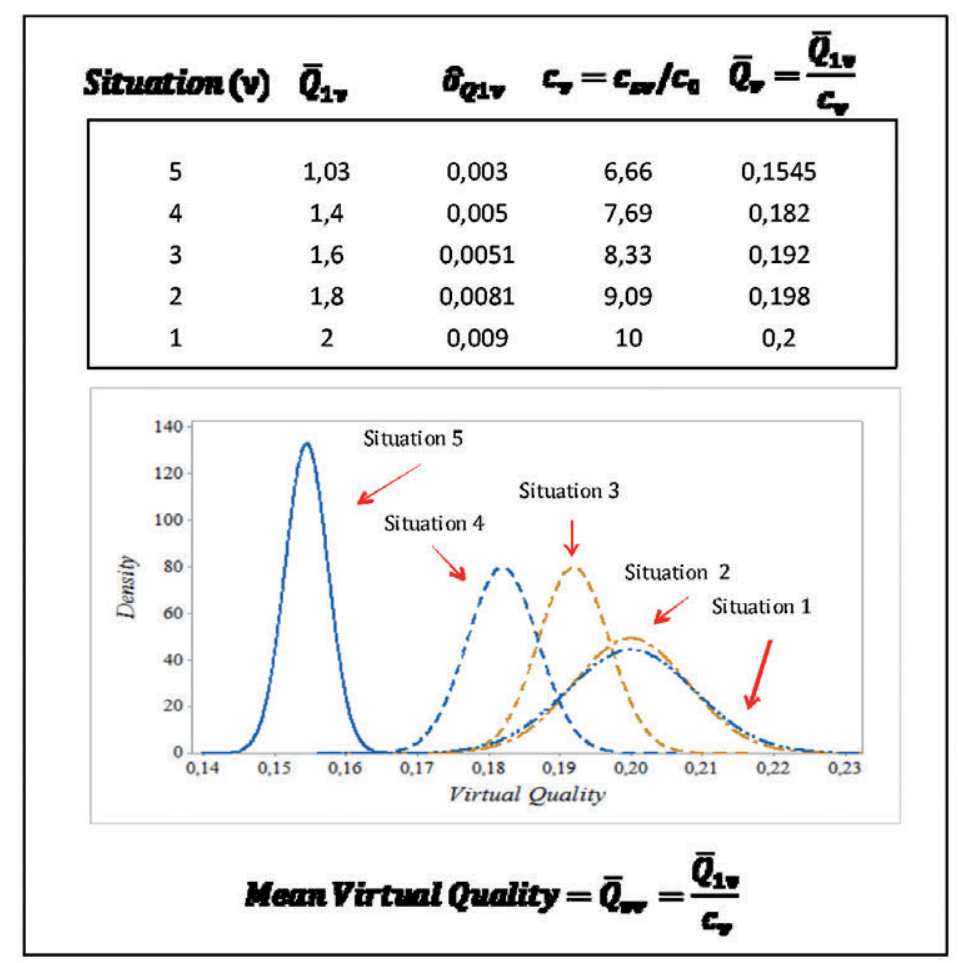

We can conclude that the point of sale in situation 5 appears as unquestionably to be the best in the average level and the variability of the virtual quality, which expresses the ratio between cost and earnings. 


\section{CONCLUSIONS}

We have seen how the information system establishes the "vital lymph" of the control, but cannot be absolutely considered equal to a "white noise", as it must be very structured so as to approximate the property of being sufficient and complete, in order to allow the immediate survey - through the use of statistical control charts - of the anomalies of the main characteristics of the product and their corrections.

That requires the integrated use of the know-how available of the productive process and their respective experimental completion (e.g. by means of statistical design of experiments).

We really hope that the examples we gave have shown the great scientific, technical and organizational diligence we have to put in order to achieve a quality of goods competitive and optimal earnings.

\section{REFERENCES}

[1] A.A.V.V. Zanella A. (1995). La statistica per lo sviluppo dell'azienda. Il quaderno dell'Istituto Guglielmo Tagliacarne, maggio, 69-97.

[2] A.A.V.V. (2000), Zanella A. Ed. Valutazione della Qualità e Customer Satisfaction: il Ruolo della Statistica. Vita e Pensiero, Milano.

[3] Zanella A., Boari G., Zappa D. (2003). Multivariate Models and Methods in Technology. Atti del Convegno intermedio della SIS: Analisi statistica multivariata per le Scienze economico- sociali, le Scienze naturali e la tecnologia (2003). RCE Edizioni, Napoli: 83-97.

[4] Cascini E. (1995). Produzione e tecnologia: una testimonianza aziendale. Il quaderno dell'Istituto Guglielmo Tagliacarne, maggio, 101-120.

[5] Cramèr H. (1958). $8^{\text {th }}$ ed. Mathematical Methods of Statistics. Princeton University Press, Princeton.

[6] Graybill F.A. (1961). An Introduction to linear Statistical Models. McGraw-Hill, New York.

[7] Johnson R.A. and Wichern D.W. (1992). Applied Multivariate Statistical Analysis. Prentice - Hall, Inc., NJ.

[8] Montgomery D. (1991). Statistical Quality Control. Wiley \& Sons, New York, $2^{\text {nd }} \mathrm{Ed}$.

[9] Zanella A. (1965). Approach to quality control in chemical processes: some example for polymerization. Proceedings of the $X$ Conference of European Organization for Quality Control - Summaries: 74-83. Stockholm.

[10] Zanella A., Bertoni L., D’Alessandro V. (1984). Il controllo nel processo produttivo. Atti del Convegno dell'Associazione Italiana per la Qualità (AICQ): La cultura della Qualità per la ripresa economica. Vol. 3: 135-209. Milano. 
[11] Zanella A.,Vicario G. (2010). Constructs and methods of statistical quality control. The role of the Italian Statistical Society. Statistica Applicata. Vol. 22, 3: 253 277, Milano.

[12] Zanella A. (1995). Total quality and the role of statistics, Proceedings of the 1st World Conference on Total Quality Control.

\begin{tabular}{ccccc}
\multicolumn{5}{c}{ APPENDIX 1} \\
Situation 1 & Situation 2 & Situation 3 & Situation 4 & Situation 5 \\
Q1 & Q1 & Q1 & Q1 & Q1 \\
2,013345732 & 1,78946068 & 1,600753863 & 1,404829083 & 1,031155179 \\
2,005534202 & 1,801748314 & 1,601056623 & 1,401347313 & 1,034501141 \\
2,001534083 & 1,80450536 & 1,600217758 & 1,395059412 & 1,033178465 \\
2,001745638 & 1,796048064 & 1,59979461 & 1,39578278 & 1,032021127 \\
1,997150025 & 1,796181732 & 1,603793601 & 1,401709746 & 1,030853005 \\
1,996771547 & 1,789630377 & 1,594810797 & 1,397709181 & 1,027495669 \\
1,985980781 & 1,80261633 & 1,603454039 & 1,398361487 & 1,03113104 \\
2,001126681 & 1,791546365 & 1,593901916 & 1,394471536 & 1,025004236 \\
2,007368869 & 1,795377552 & 1,604268933 & 1,390493552 & 1,024015917 \\
2,001844573 & 1,80612118 & 1,592713663 & 1,401246118 & 1,03019162 \\
1,989352907 & 1,789546568 & 1,599541141 & 1,399685623 & 1,030104403 \\
2,008331697 & 1,799665219 & 1,599218337 & 1,409393601 & 1,028850009 \\
1,990517889 & 1,798984777 & 1,598369324 & 1,394025085 & 1,027786291 \\
2,005248753 & 1,790664016 & 1,600312379 & 1,397514142 & 1,030120883 \\
2,005500073 & 1,808874245 & 1,601376532 & 1,395593364 & 1,028778088 \\
2,001760797 & 1,804213697 & 1,602381173 & 1,401335852 & 1,031395383 \\
1,999301929 & 1,807304744 & 1,599152602 & 1,405584273 & 1,026397308 \\
2,008527034 & 1,815884038 & 1,589790271 & 1,397658369 & 1,030517446 \\
2,009917424 & 1,789454579 & 1,602502418 & 1,395529374 & 1,032279943 \\
2,00020277 & 1,804798593 & 1,59125276 & 1,402234264 & 1,028152084 \\
2,005759919 & 1,810822439 & 1,604201601 & 1,403739004 & 1,026672171 \\
2,005387898 & 1,809118228 & 1,608880847 & 1,409427352 & 1,035073197 \\
1,999572441 & 1,799882539 & 1,601997649 & 1,407599046 & 1,033125344 \\
2,001243636 & 1,806448633 & 1,599276317 & 1,404199084 & 1,029244927 \\
1,997589697 & 1,806708343 & 1,597129975 & 1,398427059 & 1,031482911 \\
2,006628829 & 1,780458916 & 1,60147479 & 1,411550613 & 1,031262495 \\
1,998272311 & 1,801168453 & 1,599961432 & 1,407544933 & 1,030137073 \\
2,000992954 & 1,800528556 & 1,598465884 & 1,399256625 & 1,031627923 \\
2,006477123 & 1,797398769 & 1,594885467 & 1,40027899 & 1,029968993 \\
2,000710968 & 1,801980664 & 1,593029907 & 1,397064388 & 1,024056658 \\
& & & &
\end{tabular}

